\title{
XI International Mycological Congress: Guiding Vote on nomenclature proposals to amend Chapter F of the International Code of Nomenclature for algae, fungi, and plants
}

\author{
Tom W. May ${ }^{1}$ and Andrew N. Miller ${ }^{2}$
}

${ }^{1}$ Royal Botanic Gardens Victoria, 100 Birdwood Ave, Melbourne, Victoria 3004, Australia. Corresponding author e-mail: tom.may@rbg.vic.gov.au ${ }^{2}$ Illinois Natural History Survey, University of Illinois, Champaign, IL 61820, USA

\begin{abstract}
Results are provided for the Guiding Vote on the seven formal proposals to amend the International Code of Nomenclature for algae, fungi, and plants to be decided by the Fungal Nomenclature Session (FNS) of the XI International Mycological Congress in July 2018. The ballot for the Guiding Vote was provided online. There were 520 valid ballots, submitted by mycologists from 42 countries, belonging to 23 eligible groups and societies, along with authors of proposals. Two proposals F-005 and F-006, both concerning DNA sequences as types, exceeded the $75 \%$ No vote that is the threshold above which proposals are considered rejected by the FNS unless formally re-introduced. Two options for amendments to future procedures for the Guiding Vote are proposed: adding eligibility via publication of a nomenclatural novelty among fungi and removing eligibility via membership of IMA MMOs.
\end{abstract}

Key words: Author citations, DNA types, Governance, ICN, Nomenclature, Sanctioned names, Typification.

Article info: Received 4 July 2018; Published 13 July 2018.

\section{INTRODUCTION}

Seven formal proposals to amend Chapter F of the International Code of Nomenclature for algae, fungi, and plants were published in April 2018 (Hawksworth 2018), followed by a Synopsis of proposals (May \& Redhead 2018). These proposals will be considered at the Fungal Nomenclature Session (FNS) of the XI International Mycological Congress (IMC) to be held on Thursday 19 July 2018 in the plenary hall of the Puerto Rico Convention Center, San Juan, Puerto Rico. All persons registered for at least that day of the Congress are eligible to attend and vote in the FNS (each person eligible to attend has one vote, and there are no institutional votes). Prior to the Congress, as set out in the Shenzhen Code (Turland et al. 2018), a Guiding Vote is held to provide an indication of the views of mycologists on the formal proposals to amend the Code. This Guiding Vote follows the long-established procedure of a "mail vote" prior to each Nomenclature Section of an International Botanical Congress (IBC).

Eligibility for the Guiding Vote of the IMC is set out in Provision 8 of Division III of the Code (Turland et al.2018). Eligible voters include: (1) authors of proposals, (2) members of the Nomenclature Committee for Fungi (NCF), (3) members of the International Mycological Association (IMA), and of its Member Mycological Organizations (MMOs), and (4) members of any additional organizations nominated by the Fungal Nomenclature Bureau (FNB). This provision is a recent addition to the Code, proposed as a result of the deliberations of the Special Subcommittee on Governance of the Code with Respect to Fungi, which successfully recommended shifting the governance of fungal nomenclature to IMCs (May 2017, Hawksworth et al. 2017). For the IMC Guiding Vote, the Special Subcommittee suggested replication of procedures already in place for IBCs, in terms of eligible voters being members of the relevant peak international body for taxonomy. For IBCs, the peak body is the International Association for Plant Taxonomy (IAPT). When the Code was amended at the Shenzhen IBC, in relation to decisions to be made at IMCs, the IMA was recognized as the corresponding body to the IAPT for fungi. In addition, in order to maximize participation by mycologists in the IMC Guiding
Vote, eligibility was expanded to include Member Mycological Organizations of the IMA. Nevertheless, it was noted that there was potential to improve coverage of mycologists by geography and specialisms, which could be achieved by the FNB nominating further eligible organizations (May 2017). For the IMC11 Guiding Vote, the FNB (in consultation with the IMA) added four organizations, all with an international or continental scope (African Mycological Society, La Asociación Latinoamericana de Micología, International Association for Lichenology, and International Commission on the Taxonomy of Fungi - ICTF; May \& Redhead 2018). According to the statutes of the IMA, "Membership in the IMA is open to all full congress registrants of the most recent International Mycological Congress until the following congress, [and] to MMOs ... The individual members of MMOs of the IMA are also members of the IMA" (http://www.ima-mycology.org/society/statutes). For the Guiding Vote, the FNB interpreted membership of the IMA as including those registered to attend IMC11, and not only the previous IMC in 2014 (otherwise young mycologists who were not yet active at the time of IMC10 would be disenfranchised). There are currently 17 IMC MMOs, which resulted in 23 groups or societies, along with authors of proposals, being eligible to participate in the 2018 Guiding Vote.

We provide a breakdown of the results of the IMC11 Guiding Vote, along with an analysis of the participation of mycologists by eligibility category and geography. Because access to the Guiding Vote online is a new procedure, across both the IBC and IMC, we also address the following questions: (1) are ineligible people voting?; (2) can the procedures be improved?; and (3) should the eligibility criteria be amended?

\section{THE ONLINE BALLOT}

The ballot consisted of seven questions, one for each proposal, along with four questions establishing the eligibility of the voter (name, e-mail, institution, and a choice of one or more eligibility groups) and an optional question for comments. The ballot was made available online and the link to the ballot was distributed to 
eligible groups. Information about the Guiding Vote, including the link, was also placed on the IMA website. The ballot was open for 27 days, from 22 May to 17 June 2018.

Testing of various online voting systems showed that some are not accessible in some countries. Therefore, the Guiding Vote was carried out using the SmartSurvey online voting portal, which is globally accessible, and also allows for provision of the ballot via an "https" web address and Secure Sockets Layer (SSL) encryption of voting data. We received a single report of the Guiding Vote weblink not being accessible, in which case a ballot was completed for the voter by the Secretary.

There was difficulty in establishing contact with some societies whose members were eligible to vote, because information on the IMA website with contact details for the 17 IMA MMOs was in some cases out of date. For some societies, several approaches were made, sometimes to different office bearers, before contact was established. Each eligible society was asked to provide the link to the Guiding Vote to their members. All but one society confirmed that this message was received. However, a few societies did not have the facility to send e-mails to all members. In addition, some societies (particularly in Europe) noted that the main interest of many of their membership was edible fungi rather than taxonomy and nomenclature. For the IMA, the e-mail distribution list used by that organization is around 3000 mycologists, providing much greater coverage than only those registered to attend IMC11(i.e. IMA members as interpreted by the FNB).

In relation to privacy of the data collected, only the Secretary of the Fungal Nomenclature Bureau (TM) and the Returning Officer (AM) had access to the results of the Guiding Vote ballot. Once the ballot closed, the results were downloaded for analysis and deleted from the online voting portal. Once analyses were completed, all personal identifying data were deleted.

\section{RESULTS OF THE GUIDING VOTE}

\section{Votes on proposals}

The online ballot required indication of one of five options for each proposal. The options were Yes, No, Special-purpose Committee, Editorial Committee, and Abstain. Totals in Table 1 are only for valid ballots (see below) and do not include abstentions. Discounting abstentions, a much greater number of opinions were provided on the two proposals on DNA as type in the absence of physical specimens (F-005 and F-006) with 516 and 511 total votes respectively, compared to opinions on the other five proposals (between 312 and 373 total votes). On the ballot, Prop. F-001 and F-002 were indicated as alternatives. Logically, a Yes vote for F-001 was not compatible with a Yes vote for F-002, but this combination of votes occurred in 49 ballots, perhaps indicating some difficulty in interpreting these proposals. Two proposals exceeded $75 \%$ No (F-005, with $88.8 \%$ No and F-006, with $86.1 \%$ No). None of the proposals reached $60 \%$ Yes, although F-003 was just short at $59.3 \%$ Yes. According to Provision 5.5 of Division III of the Shenzhen Code (Turland et al. 2018), which also relates to the Guiding Vote for the Fungal Nomenclature Session (see Provision 8.1), "any proposal to amend the Code that receives $75 \%$ or more 'no' votes in the preliminary guiding vote is automatically rejected" at the Fungal Nomenclature Session - unless a proposal to discuss it is moved by a registered attendee and supported (seconded) by at least five other attendees. Thus, if the two proposals concerning DNA as type (F-005 and F-006) are to be debated at the San Juan FNS, they will have to be formally re-introduced. It should be noted that Lücking et al. (2018) have added further proposals about DNA as type, intended to be introduced "from the floor" at the FNS, as allowed under Provision 5.7 of Division III of the Code (Turland et al.2018).

\section{Valid and eligible ballots}

A total of 531 ballots were successfully completed. This response was especially gratifying as the mail ballot for the Shenzhen IBC received just 82 (see below). A further 72 ballots that were incomplete were discounted. There were two pages to the online ballot. The first with the proposals, the second with questions about eligibility (such as name and eligible organization). All incomplete ballots had complete answers for the first page, but lacked eligibility information (or in one case had an ineligible organization provided for affiliation). Information from the first page was only recorded in the online vote system once the voter moved to the second page. Therefore, people filling out these incomplete ballots presumably realized that they were ineligible once they moved to the second page of the ballot (or else did not wish to record their personal details).

Among complete ballots, there were two cases where a single person voted multiple times (one twice and one three times). One ballot contained random characters in the responses to the personal information. The online voting system collected information on the IP address of the voter. Apart from the duplicated ballots submitted by the same voters, there were also some cases of duplicate IP addresses on different ballots. However, all these ballots were

Table 1. Valid votes for each option in the IMC11 Guiding Vote. \%No is calculated as proportion of Total votes cast (excluding abstentions).

\begin{tabular}{|c|c|c|c|c|c|c|c|c|}
\hline Proposal & Topic & Yes & No & $\begin{array}{l}\text { Special-purpose } \\
\text { Committee }\end{array}$ & $\begin{array}{l}\text { Editorial } \\
\text { Committee }\end{array}$ & Abstain & $\begin{array}{l}\text { Total (excluding } \\
\text { abstentions) }\end{array}$ & $\%$ No \\
\hline F-001 & Lectotype only for sanctioned names & 158 & 116 & 17 & 21 & 208 & 312 & 37.2 \\
\hline F-003 & Remove colon & 192 & 107 & 16 & 9 & 196 & 324 & 33.0 \\
\hline F-004 & Remove colon & 181 & 103 & 23 & 10 & 203 & 317 & 32.5 \\
\hline F-006 & DNA as type & 41 & 440 & 4 & 26 & 9 & 511 & 86.1 \\
\hline F-007 & Identifier replace author citation & 91 & 249 & 19 & 14 & 147 & 373 & 66.8 \\
\hline
\end{tabular}


submitted by different individual voters, in situations where several mycologists were at the same institution.

Cross check of eligibility groups with known membership showed that for the NCF all those selecting this group were in fact members. However, for the group "Author of proposal", 15 voters selected this group incorrectly. Of these, five also selected other eligibility groups, and one was an office bearer of an eligible society but did not select this option. A check with the other nine revealed that almost all had misinterpreted the Zamora et al. (2018) publication (that appeared around the time the Guiding Vote went live) as containing a formal proposal. Two of the nine were in fact members of an eligible organization; ballots from the other seven were deemed ineligible. For the group ICTF, four voters selected this group incorrectly: in three cases voters were also eligible under other categories (incorrect selection appeared to be due to voters being members of ICTF Subcommissions or Working Groups rather than the ICTF itself) and for the other case, the voter was not a member of any eligible group and their ballot was deemed ineligible. Among voters who selected eligibility groups that were national or international organizations, all details provided were consistent with the indicated membership (such as the institution of the voter being in the same country as the national mycological society selected or the voter being an office bearer of the society selected), although a cross-check against membership registers was not carried out.

When determining eligibility of ballots, where voters selected an inapplicable eligibility option along with other eligibility options, ballots were retained. Otherwise, 11 duplicate, nonsense or ineligible ballots were removed, yielding 520 valid ballots. While it is possible that there were other undetected ineligible ballots, any further ineligible voting is considered to have been at such a low rate (in the order of one to several ballots) as to have no effect on the outcome.

Eligible voters belonged to between one and eight of the 24 eligibility groups (including authors of proposals), but mostly $(89.2 \%)$ one or two groups (mean 1.4 ) (Table 2). The groups with the most eligible voters were the Mycological Society of America - MSA (116), German Society for Mycology (115), Dutch Mycological Society (108), International Mycological Association (88), British Mycological Society - BMS (51), International

Table 2. Breakdown of valid ballots by eligibility groups. Note that the total ballots in this table is greater than the number of ballots cast, due to voters often belonging to more than one eligibility group. Categories of eligibility groups include those set out in Provision 8 of Division III of the Code (DIV III), among which are the International Mycological Association (IMA) and societies that are a Member Mycological Organization of the IMA (IMA MMO); along with four additional groups approved by the Fungal Nomenclature Bureau (FNB). Totals do not include incorrect assignments by voters to the eligibility groups 'Authors of proposals' and 'International Commission on the Taxonomy of Fungi'.

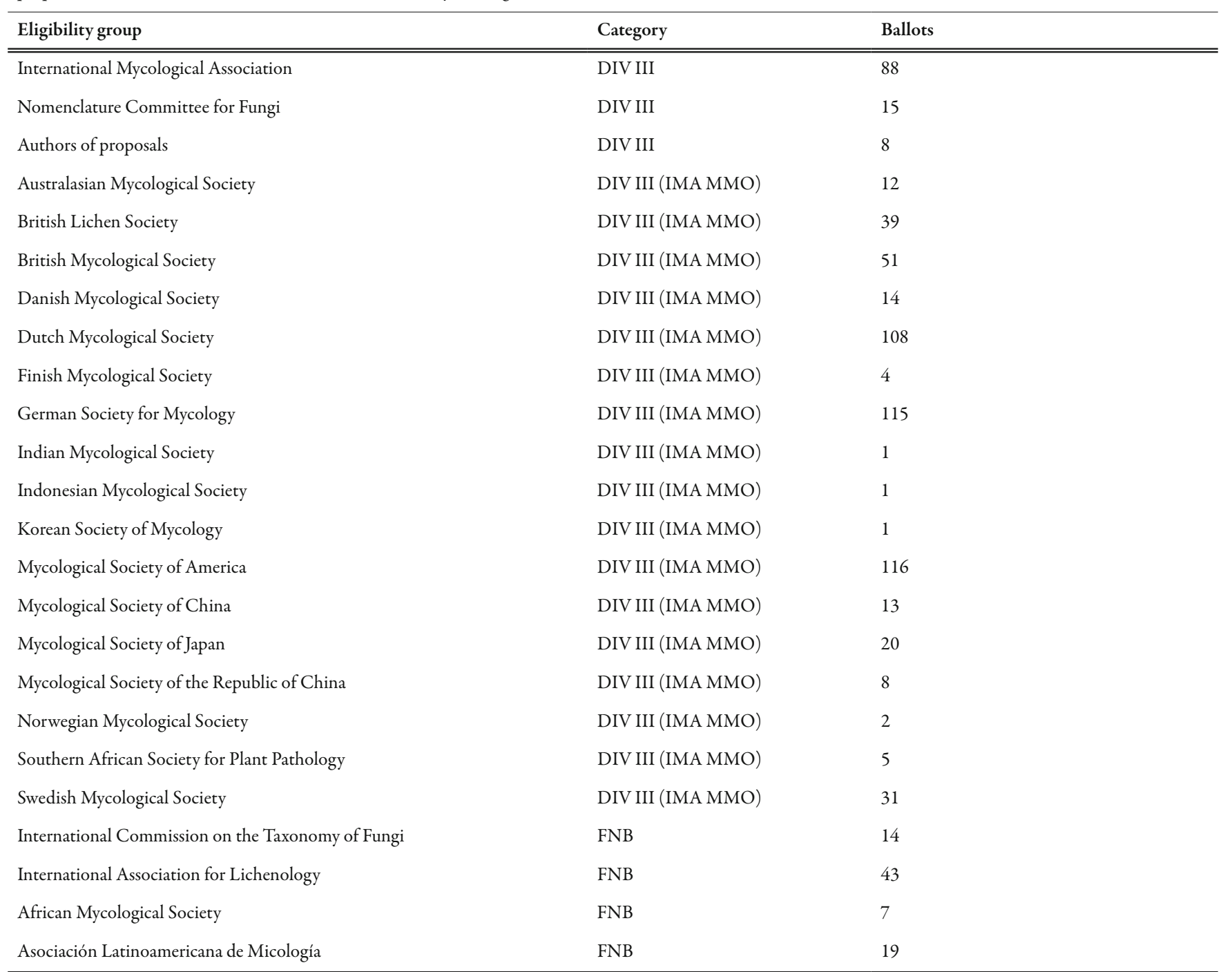


Table 3. Breakdown of valid ballots by country and region.

\begin{tabular}{llll}
\hline Region & No. ballots & Region subtotal (\%) \\
\hline \hline Africa & & & \\
& Nigeria & 1 & \\
& South Africa & 8 & $9(1.7 \%)$
\end{tabular}

Asia

$\begin{array}{ll}\text { China } & 13 \\ \text { India } & 1 \\ \text { Indonesia } & 1 \\ \text { Iran } & 1 \\ \text { Japan } & 20 \\ \text { Malaysia } & 1 \\ \text { South Korea } & 1 \\ \text { Taiwan } & 8 \\ \text { Thailand } & 7\end{array}$

$53(10.7 \%)$

Europe

$\begin{array}{ll}\text { Austria } & 5 \\ \text { Belgium } & 12 \\ \text { Czech Republic } & 6 \\ \text { Denmark } & 10 \\ \text { Estonia } & 1 \\ \text { Finland } & 4 \\ \text { France } & 2 \\ \text { Germany } & 109 \\ \text { Greece } & 1 \\ \text { Italy } & 3 \\ \text { Luxembourg } & 3 \\ \text { The Netherlands } & 105 \\ \text { Norway } & 4 \\ \text { Poland } & 3 \\ \text { Slovakia } & 1 \\ \text { Slovenia } & 1 \\ \text { Spain } & 16 \\ \text { Sweden } & 32 \\ \text { Switzerland } & 3 \\ \text { U.K. } & 16\end{array}$

$337(64.8 \%)$

North America

$\begin{array}{ll}\text { Canada } & 15 \\ \text { Costa Rica } & 1 \\ \text { Cuba } & 1 \\ \text { Mexico } & 2 \\ \text { U.S.A. } & 68\end{array}$

$87(16.7 \%)$

Oceania

Australia $\quad 11$

New Zealand $\quad 10$

$21(4.0 \%)$

South America

Argentina
Table 3. (Continued).

\begin{tabular}{llll}
\hline Region & No. ballots & Region subtotal (\%) \\
\hline \hline & Brazil & 7 & \\
Chile & 2 & \\
& Colombia & 2 & $\mathbf{1 3}(2.5 \%)$ \\
& & & $\mathbf{5 2 0}$
\end{tabular}

Association for Lichenology (43), British Lichen Society (39), and Swedish Mycological Society (31). Ballots by members of one or more of these eight groups accounted for $87.1 \%$ of ballots. All other groups had 20 or less eligible voters. Eighty-two voters ( $15.8 \%$ ) belonged to at least one of the four eligibility groups added by the FNB, although some voters who indicated one of these four eligibility groups were also members of the IMA and/or of IMA MMOs.

\section{Geography}

There was no option on the ballot to indicate the country of the voter. Therefore, this was established from the institution and eligibility groups indicated by each voter; with the country domain in their e-mail address as a cross check. Voters came from 42 countries (Table 3), with mycologists from Europe (64.8\%), North America (16.7\%) and Asia (10.2\%) submitting $91.7 \%$ of the valid ballots. The country with the most voters was Germany (109), followed by The Netherlands (105), the USA (68), Sweden (32), Japan (20), Spain (16), and the UK (16). The breakdown by country more or less paralleled the breakdown by eligibility group, as far as national mycological societies, except for the USA and UK, because their national societies (MSA and BMS) have a significant proportion of foreign members, the proportion of voters from these countries $(16.2 \%)$ is somewhat less than the proportion of these two national societies among voters (26.9\% are members of one or both these societies). Where a mycological society for a particular country was not an IMA MMO, there were no or very few ballots submitted by mycologists from that country, such as, for example, for France (2), Greece (1), Italy (3), and the Russian Federation (0). There was very low representation of voters and countries from Africa (1.7\% voters, from two countries) and South America (2.5\% of voters, from four countries). For Prop. F-005, among the 13 countries with 10 or more ballots, the No vote (which overall was $88.8 \%$ ) was more than $75 \%$ for all with the exception of the USA $(70.6 \%$ No, of total minus abstentions $n=68)$, the UK $(66.7 \%$ No, $n=$ 15), Canada (66.7 \% No, $n=15)$, New Zealand (60.0 \% No, $n=$ 10 ), and of these, due to there usually also being some votes for Editorial or Special Purpose Committee, the number of Yes votes was no more than $25 \%$ except for UK (33.3\% Yes).

\section{Affiliation}

Voters were asked to indicate their institution, with an option to write "unaffiliated". Overall, 293 (56.3\%) voters were associated with an institution or company, 119 (22.9\%) indicated "unaffiliated", $106(20.4 \%)$ provided the eligible society as their affiliation, and two $(0.4 \%)$ were freelancers or contractors. The 
proportion of unaffiliated voters was similar across organizations, except that a high proportion of those voting from the Dutch Mycological Society $(88.9 \%, n=108)$ and the German Society for Mycology $(75.7 \%, n=115)$ were not associated with an institution. By geography, for countries with more than 10 voters, those with a majority of voters associated with an institution were Canada (100\%), China (100\%), Japan (95\%), Australia (91\%), Spain (88 \%), the USA (88\%), New Zealand (80\%), the UK (69\%), Belgium (58\%) and Sweden (53\%), while those with a minority were Germany (27\%), and The Netherlands (15\%). For Prop. F-005, the No vote was $82.0 \%(n=293)$ for those affiliated with an institution, compared to $97.4 \%(n=227)$ for all other voters. Except for Prop. F-005 and F-006, for which there were very few abstentions, it was notable that abstentions were lower among voters associated with an institution (for example, $31.4 \%$ Abstain, for Prop. F-001) than among the remaining voters (51.1 $\%$, Abstain, for the same Proposal).

\section{Nomenclatural novelties}

Given the possibility of widening the eligibility criteria (see below) the proportion of voters who have introduced a nomenclatural novelty (new name or new combination) among fungi was investigated. By cross matching names of voters against authors of fungal novelties in MycoBank (http://www.mycobank.org), about half of the Guiding Vote participants $(53.8 \%$ ) were found to have published at least one nomenclatural novelty of fungi. Among mycologists with institutional affiliations the proportion who had published fungal nomenclatural novelties was much higher, at $76.1 \%(n=293)$, compared to $25.1 \%$ for those with no institutional affiliation $(n=227)$. When the criteria of publishing a nomenclatural novelty and attending IMC11 were considered together, $56.1 \%$ met these joint criteria.

\section{Comparison to IBC Guiding Vote}

The Guiding Mail Vote for the International Botanical Congress has been a hard copy ballot, which for the last several Congresses could be mailed or submitted by electronic means such as fax or e-mail. For the 2011 Melbourne Congress 140 ballots were submitted, while for the 2017 Shenzhen Congress just 82 ballots were submitted (McNeill et al. 2011, Turland et al. 2017). Those eligible to participate in the Guiding Vote of the IBC are: (1) authors of proposals, (2) members of permanent nomenclature committees, and (3) members of the International Association for Plant Taxonomy (IAPT). The total eligible persons for the Melbourne IBC vote was 1400 - of whom $10 \%$ participated (McNeill et al. 2011).

For the IMC Guiding Vote, the pool of eligible participants is in the order of many thousands, given that attendees at International Mycological Congresses alone usually number around 1000 or more, and some of the eligible organizations have memberships of 1000 or more. Therefore, the percentage participation in this IMC Guiding Vote, while not able to be estimated accurately, is of the same order as that for recent IBC Guiding Votes. However, the absolute number of mycologists participating in the IMC Guiding Vote was more than six times as many as participated in the last IBC Guiding Vote in Shenzhen (and more than three times the participation at the previous IBC in Melbourne). On the basis of this relatively high numerical participation, the inaugural Guiding Vote can be considered a success in engaging mycologists, no doubt due at least in part to the contentious nature of the two proposals that concern the use of DNA sequences as types (Lücking et al. 2018, Thines et al. 2018, Zamora et al. 2018). Nevertheless, it was apparent that participation in the Guiding Vote was uneven across eligible groups in relation to the size of their membership, dominated by members of eight of the 23 groups, and uneven across geography.

\section{Comments}

Apart from comments reflecting the choice of vote on particular proposals, and general positive feedback about the opportunity to participate, a number of issues were raised in the optional comment field. Contrasting views were expressed about the breadth of eligibility: one voter pointed out that some societies have many members who are not taxonomists, yet all members of such societies are eligible to vote; while another voter was appreciative that the issues were being presented "to a broader public, like ordinary members of mycological societies". One voter mentioned that retired mycologists may not continue their society membership on retirement, and those in this situation are ineligible to vote. One voter suggested amending the current procedures to open the Guiding Vote to all mycologists who have published on fungal taxonomy or nomenclature (eligibility established by providing publication or link to publication) rather than via membership of eligible organizations. In addition, there were several comments about the difficulty of understanding terminology, such as "sanctioning works" and the difference between a Special-purpose committee and the Editorial committee.

\section{Amendments to eligibility}

On the one hand, eligibility for the Guiding Vote is not well balanced by geography, being dependent firstly on those national societies that are IMA MMOs, and secondly on those societies contacting their members. On the other hand, it could be argued that societies that pay dues to the IMA support the infrastructure of fungal nomenclature, by enabling the IMA to organize International Mycological Congresses, at which Fungal Nomenclature Sessions occur, and publish IMA Fungus, in which articles on fungal nomenclature appear. There is also an issue of the degree to which the Guiding Vote should be open to nonprofessional mycologists. About half of the non-professional mycologists did not vote on proposals other than the highly publicized pair of proposals on DNA as type (compared to around a third of mycologists associated with an institution). It should be noted that the Guiding Vote is not the only way that opinions can be registered prior to the Fungal Nomenclature Session. Several publications, some with numerous authors, provided opinions on particular proposals (Lücking et al. 2018, Thines et al. 2018, Zamora et al. 2018).

\section{NEW PROPOSALS}

Two new proposals are introduced here for consideration at the IMC11 FNS "from the floor", using numbering that follows on from the previously published proposals (Hawksworth 2018). 


\section{(F-008) Proposal to amend Provision 8.3 of Division III}

Amend Provision 8.3 of Division III [see above for full text of this Provision] as follows (new text in bold, deleted text in strikethrough):

"A guiding vote on proposals to amend the Code relating solely to names of organisms treated as fungi is organized by the Fungal Nomenclature Bureau in conjunction with the International Mycological Association (IMA) to coincide with the publication of the Synopsis of proposals. No accumulation or transfer of votes is permissible in this vote. The following persons are entitled to vote:

(a) Individual members of the IMA;

(b) Individual members of organizations affiliated with the IMA;

(c) Individual members of other organizations approved by Fungal Nomenclature Bureau;

(d) Authors of proposals to amend the Code relating solely to names of organisms treated as fungi;

(e) Members of the Nomenclature Committee for Fungi;

(f) Mycologists who have published at least one nomenclatural novelty among organisms treated as fungi."

This proposal addresses the lack of geographic balance among eligible organizations, adding mycologists who may not be members of relevant societies, but nevertheless have direct experience of fungal nomenclature through providing a new name or new combination for a fungus. Opening up the Guiding Vote in this way is administratively much simpler than the Fungal Bureau of Nomenclature adding further eligible groups, on a caseby-case basis. Should this proposal be adopted, in the Guiding Vote ballot eligibility via publication of a nomenclatural novelty could be indicated by providing one such fungal name (ideally with the repository identifier for the name), allowing a cross check against information in MycoBank. This is a simpler validation than requiring full details of publications containing novelties. Of course, the Guiding Vote would still be open to mycologists who have not published nomenclatural novelties, as long as they matched at least one of the other eligibility criteria.

\section{(F-009) Proposal to amend Provision 8.3 of Division III}

Amend Provision 8.3 of Division III as follows [see above for full text of this Provision] as follows:

“(a) Individual members of the IMA, apart from members of IMA Member Mycological Organizations (MMOs) unless they are IMA members through attendance at the relevant International Mycological Congress; (b) Individual members of organizations affitiated with the IMA;"

Adoption of this proposal would remove the current eligibility of IMA MMOs, making administration of the Guiding Vote simpler, given the practical difficulties of contacting some 21 organizations (in addition to the IMA, the NCF and authors of proposals) to inform them of the eligibility of their members to participate in the Guiding Vote. Removal of IMA MMO membership as an eligibility category, using the 2018 results as a baseline, will most likely lead to reduced participation in relative terms by unaffiliated mycologists who have not published nomenclatural novelties among fungi (and are not attending the relevant IMC). If both Prop. F-008 and F-009 were adopted, about half of those who participated in the 2018 Guiding Vote would remain eligible, while opening up the Guiding Vote to a greater number of taxonomic mycologists across the globe

\section{FUTURE PROCEDURES}

In relation to procedures for future IMCs, the online form could be improved by placing the eligibility questions first, followed by the proposals. The longer lead time in the run up to IMC12 in 2022, in comparison to the very short timelines for procedures in the lead up to IMC11, means that there will be an opportunity to publish information on procedures well ahead of the IMC12 Guiding Vote. IMA Fungus should remain the main venue for key publications on changes to fungal nomenclature, such as the Proposals to amend the Code and the Synopsis of proposals, but it would also be useful for information about the process of publishing proposals and participation in the Guiding Vote to be provided to a wide range of societies (not just IMA MMOs) for inclusion in their newsletters or journals.

\section{ACKNOWLEDGEMENTS}

We thank David Hawksworth for helpful feedback and Dominik Begerow (IMA webmaster) for placing information about the Guiding Vote on the IMA website. TM thanks the Royal Botanic Gardens Victoria for financial support for the subscription to the online ballot portal, Sara Maroske for helpful feedback on this report and office bearers of the eligible societies for facilitating contact with their members at relatively short notice.

\section{REFERENCES}

Hawksworth DL (ed.) (2018) Proposals for consideration at IMC11 to modify provisions solely related to fungi in the International Code of Nomenclature for algae, fungi, and plants. IMA Fungus 9: (i)-(vii).

Lücking R, Kirk PM, Hawksworth DL (2018) Sequence-based nomenclature: a reply to Thines et al. and Zamora et al. and provisions for an amended proposal "from the floor" to allow DNA sequences as types of names. IMA Fungus 9: 185-198.

May TW (2016) Report of the Special Subcommittee on Governance of the Code with Respect to Fungi. Taxon 65: 249-253.

May TW, Redhead SA (2018) Synopsis of proposals on fungal nomenclature: a review of the proposals concerning Chapter F of the International Code of Nomenclature for algae, fungi, and plants submitted to the XI International Mycological Congress, 2018. IMA Fungus 9: (ix)-(xiv).

McNeill J, Turland NJ, Monro AM, Lepschi BJ (2011) XVIII International Botanical Congress: Preliminary mail vote and report of Congress action on nomenclature proposals. Taxon 60: 1507-1520.

Thines M, Crous PW, Aime MC, Aoki T, Cai L, et al. (2018) Ten reasons why a sequence-based nomenclature is not useful for fungi anytime soon. IMA Fungus 9: 177-183.

Turland NJ, Kempa M, Knapp S, Senková E, Wiersema JH (2017) XIX International Botanical Congress: preliminary guiding mail vote on nomenclature proposals. Taxon 66: 995-1000

Turland NJ, Wiersema JH, Barrie FR, Greuter W, Hawksworth DL, et al. (2018) International Code of Nomenclature for algae, fungi, and plants 
(Shenzhen Code) adopted by the Nineteenth International Botanical Congress Shenzhen, China, July 2017. [Regnum Vegetabile no. 159.] Glashütten: Koeltz Botanical Books.

Zamora JC, Svensson M, Kirschner R, Olariaga I, Ryman S, et al. (2018)

Considerations and consequences of allowing DNA sequence data as types of fungal taxa. IMA Fungus 9: 167-175. 